\title{
BMJ Open School-based intervention for the prevention of HPV among adolescents: a cluster randomised controlled study
}

\author{
Maria Grandahl, ${ }^{1}$ Andreas Rosenblad, ${ }^{2}$ Christina Stenhammar, ${ }^{1}$ Tanja Tydén, ${ }^{1}$ \\ Ragnar Westerling, ${ }^{1}$ Margareta Larsson, ${ }^{3}$ Marie Oscarsson, ${ }^{1,4}$ Bengt Andrae, ${ }^{5}$ \\ Tina Dalianis, ${ }^{6}$ Tryggve Nevéus ${ }^{3}$
}

To cite: Grandahl M, Rosenblad A, Stenhammar C, et al. School-based intervention for the prevention of HPV among adolescents: a cluster randomised controlled study. BMJ Open 2016;6:e009875. doi:10.1136/bmjopen-2015009875

- Prepublication history and additional material is available. To view please visit the journal (http://dx.doi.org/ 10.1136/bmjopen-2015009875).

Received 1 September 2015 Accepted 8 December 2015

\section{CrossMark}

For numbered affiliations see end of article.

\footnotetext{
Correspondence to Dr Maria Grandahl; maria.grandahl@pubcare.uu. se
}

\section{ABSTRACT}

Objective: To improve primary prevention of human papillomavirus (HPV) infection by promoting vaccination and increased condom use among upper secondary school students.

Design: Cluster randomised controlled trial. Setting: 18 upper secondary schools in Sweden. Participants: Schools were first randomised to the intervention or the control group, after which individual classes were randomised so as to be included or not. Of the 832 students aged 16 years invited to participate during the regular individual health interview with the school nurse, $751(90.2 \%)$ agreed to participate and $741(89.1 \%)$ students completed the study.

Interventions: The intervention was based on the Health Belief Model (HBM). According to HBM, a person's health behaviour can be explained by individual beliefs regarding health actions. School nurses delivered 30 min face-to-face structured information about HPV, including cancer risks and HPV prevention, by propagating condom use and HPV vaccination. Students in the intervention and the control groups completed questionnaires at baseline and after 3 months.

Main outcome measures: Intention to use condom with a new partner and beliefs about primary prevention of HPV, and also specifically vaccination status and increased condom use.

Results: All statistical analyses were performed at the individual level. The intervention had a significant effect on the intention to use condom $(p=0.004)$. There was also a significant effect on HBM total score $(p=0.003)$, with a 2.559 points higher score for the intervention group compared to the controls. The influence on the HBM parameters susceptibility and severity was also significant $(p<0.001$ for both variables). The intervention also influenced behaviour: girls in the intervention group chose to have themselves vaccinated to a significantly higher degree than the controls $(p=0.02)$. No harms were reported.

Conclusions: The school-based intervention had favourable effects on the beliefs about primary prevention of HPV, and increased the HPV vaccination rates in a diverse population of adolescents.

Trial registration number: NCT02280967; Results.

\section{Strengths and limitations of this study}

- This is the first school-based educational cluster randomised controlled trial targeting a diverse and representative population of adolescents of both sexes, with the aim to improve primary prevention of human papillomavirus (HPV).

- The rigorously tested and validated intervention was found to have significant favourable effects on both the behaviour and beliefs of the participants.

- Although our study was fairly large, it would have been even better if we had been able to include more participants in order to be able to go into further detail and perform more subgroup analyses.

- For logistic reasons, the follow-up of the students had to be performed in groups, meaning that students could not be randomised individually. Consequently, the groups differed somewhat at baseline.

\section{INTRODUCTION}

Infection with human papillomavirus (HPV) is one of the major causes of infectionrelated cancer worldwide. HPV is related to cancer in the cervix uteri, penis, vulva, vagina, anus and the oropharynx. ${ }^{1}{ }^{2}$ These malignancies can be effectively prevented by the prophylactic vaccination against HPV and by safe sex (condom use) in addition to the regular screening. ${ }^{3-7}$ Many countries have implemented national HPV immunisation programmes. $^{8}$ In Sweden, from 2012, girls aged 10-12 years are being offered the quadrivalent vaccine as part of the schoolbased vaccination programme administered by the school nurse, while older girls and young women are offered the vaccine in the catch-up programme administered in the primary care setting. The coverage among young women is substantially lower $(59 \%)$ than that in the lower age group (83\%). ${ }^{9}$ 
HPV infections and HPV-related diseases have increased in recent decades due to increased sexual risk taking. ${ }^{10-12}$ The highest prevalence of HPV is found among teenagers and young adults. ${ }^{13} 14$ Therefore, preventive strategies, such as the implementation of effective educational interventions among adolescents, are very much needed.

Adolescents do not receive education regarding HPV on a regular basis. The school nurses play a key role in providing such information. ${ }^{15-17}$ Adolescents have low awareness and knowledge about the virus, especially regarding the cancer risks. ${ }^{18}$ Educational school-based interventions can increase adolescents' awareness and knowledge about HPV prevention, ${ }^{19} 20$ enhance preventive behaviours for sexually transmitted infections in general $^{21}$ and reduce sexual risk taking. ${ }^{22}{ }^{23}$ Interventions can also have a beneficial effect on beliefs about HPV vaccination among girls. ${ }^{24}$ So far, very few randomised controlled trials have been conducted among adolescents with the aim to promote primary HPV prevention. ${ }^{25-27}$ As far as we know, no such trial has been performed in a diverse population of both adolescent boys and girls.

\section{Aim and hypothesis}

The overall aim was to improve primary prevention of HPV by promoting HPV vaccination and increased condom use among upper secondary school students. The hypothesis was that intervention was associated with different beliefs (different attitudes) towards HPV prevention at follow-up and that this influenced the actual behaviour.

\section{METHODS}

Study design

A cluster randomised controlled trial with measurements at baseline and at follow-up after 3 months. Cluster randomisation was used since the randomisation was first conducted at school level and thereafter classes were randomised to be included. Follow-up after 12 and 24 month are not presented in this paper.

\section{Setting}

Sweden is a multicultural country: almost a third of all children under the age of 18 years have an immigrant background. ${ }^{28}$ The Swedish upper secondary school, which the vast majority of students attend, conducts both theoretical and vocational programmes that reach out to adolescents aged 16-19 years. According to Swedish law, all students should have access to school health. The school health work is mainly preventive and involves at least a school nurse and a school physician; however, only the nurse works in the school on a regular basis. In Sweden, sexual education is mandatory in primary and secondary school, and includes topics such as anatomy, sexuality, prevention of sexually transmitted infections and reproductive health.
All first year upper secondary school students (aged 16 years) are offered a health interview with the school nurse, who provides a dialogue regarding psychosocial health, eating habits, sleep, physical activity, intake of tobacco, alcohol and drugs, as well as sexual health and relationships. This intervention is optional, although usually all students do participate in it. The interview is scheduled for approximately $1 \mathrm{~h}$ and conducted in an empathic atmosphere based on Motivational Interviewing $^{29}$ that focuses on the individual student's health and well-being.

\section{Population and sample}

First year upper secondary school students attending the regular health interview with the school nurse in the autumn semester of 2014 were eligible for participation. We excluded students who were not able to speak or write Swedish (ie, recently arrived immigrants), and adolescents with severe learning disabilities and development disorders (ie, studying at special schools). Upper secondary schools $(n=18)$ in nine municipalities in central Sweden a total of about 600000 rural and urban inhabitants who represented different socioeconomic levels-were included. The participating schools included both municipally and privately managed schools that offered vocational as well as theoretically-oriented education, and had a varying number of students.

\section{Recruitment and randomisation}

School nurses were recruited to the project via the school heads and through direct contact at a national school health conference. For logistical reasons, those working in the far north or south of Sweden were not invited. Initially 59 upper secondary schools were approached and eventually 18 of these were included; details of the recruitment are given in the flow chart in figure 1. A total of 23 school nurses working in 20 schools in 9 municipalities agreed to participate in the study. Three nurses in two schools dropped out at the start of the intervention due to heavy workload. This opportunistic selection resulted in a total of 20 school nurses working in 18 schools.

Randomisation was performed in two steps. First, in order to avoid contamination, the schools were randomised into either the intervention group or the control group. The schools were randomly drawn by administrative personnel not involved in the project. Second, 113 school classes within these schools were randomly selected to be included in the study; this number was chosen in order to achieve the desired number of students according to the power calculations (described below). The school nurses provided basic details about the classes (eg, Social science 14A), and number of students in each class. If the class consisted of less than 25 students, an additional class was allocated. The students were recruited by the school nurses, as described below. The end result was an intervention group of 394 students from 60 classes and a control group of 357 


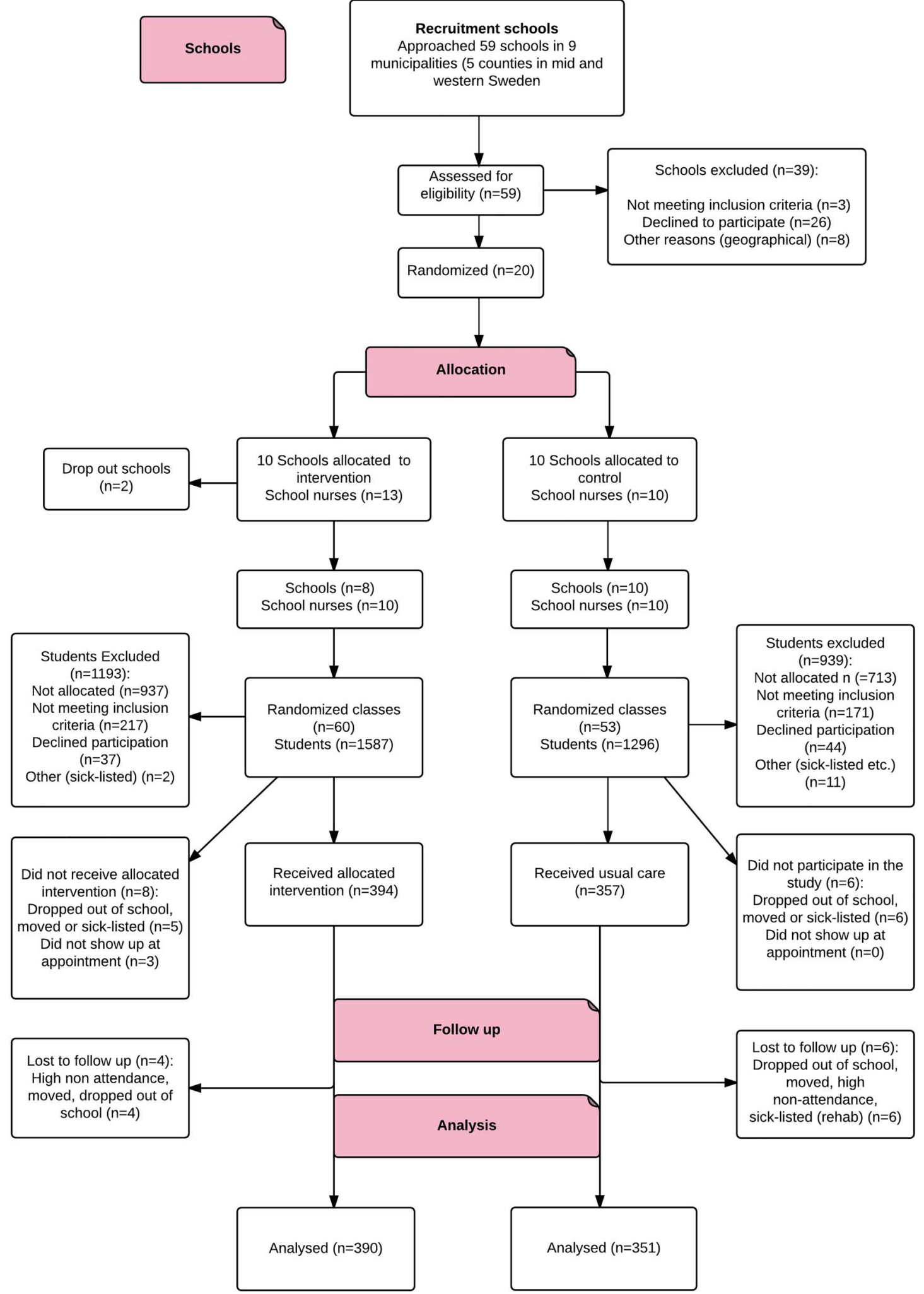

Figure 1 Flow of schools and students through trial.

students from 53 classes (figure 1). Recruitment did not begin until registration was made public.

Two school nurses in two schools dropped out during the intervention due to termination of employment and personal reasons, and they did not complete the health interviews with their allotted students. In order to compensate for these losses, which were all from the intervention group, all school nurses in the intervention group were advised to perform health interviews with an additional class. Consequently, similar classes were included in the study.

The students $(n=832)$ were invited to participate in the study when they met the school nurse for the 
general health interview. Those who agreed to participate $(n=751)$ gave informed written consent. Before the health interview started, all students were asked to complete a baseline questionnaire. A follow-up questionnaire was completed after 3 months $(n=741)$. The baseline questionnaire was completed individually at the school nurse's office while the follow-up questionnaire was given to the whole class. Students not present at this time could complete the follow-up questionnaire afterwards at the school nurse's office. School nurses were provided with checklists regarding the procedure and used log lists (protocols completed after each health interview) to assure that the intervention was performed in a uniform fashion. For obvious reasons, the school nurse could not be blinded to whether the student belonged to the intervention or control group, but the research assistant who recorded the data from the participants did not possess this knowledge.

\section{Theoretical framework}

The Health Belief Model (HBM) was used as a theoretical framework. This model has previously been used in studies about HPV and HPV vaccination, ${ }^{30}{ }^{31}$ and in interventions with the aim to increase prevention of sexually transmitted infections. ${ }^{19} 32$ According to the HBM framework, a person's health behaviour can be explained by the individual's beliefs regarding health actions. HBM includes the following central constructs: perceived susceptibility, perceived severity, perceived benefit and perceived barriers. Furthermore, sociodemographic factors, such as age, sex, ethnicity and parental education level, as well as knowledge, are recognised as factors that can indirectly influence the individual's behaviour. The main limitation of the model is that it does not consider emotional or relational aspects involved in decisions regarding health behaviour. ${ }^{33}$

\section{Intervention}

The intervention was included in the general $1 \mathrm{~h}$ face-to-face health interview. Thus, while the controls received general information, including those on sexual health, the intervention group received specific HPV education guided by HBM and a predesigned informational structure format. The school nurse showed a specially designed flipchart with pictures and brief information to the students (see example in table 1). She also handed out a specially designed leaflet. The intervention took about $30 \mathrm{~min}$ and included the following information:

- General facts about the virus;

- Viral transmission;

- What HPV can cause;

- Risk factors;

- Prevention, that is, safe sex with condom use and HPV vaccination;

- Locations where the girls could receive the vaccine free of charge in the municipality;

- Facts about the HPV vaccine;
Table 1 Example of the flip chart

\begin{tabular}{|c|c|}
\hline Student information & $\begin{array}{l}\text { School nurses' work } \\
\text { material 'chat script' }\end{array}$ \\
\hline $\begin{array}{l}\text { Prevention of HPV } \\
\text { 1. Vaccination } \\
\text { HPV vaccine protects } \\
\text { against the most common } \\
\text { HPV types that cause } \\
\text { cervical cancer and } \\
\text { condyloma (genital warts) } \\
\text { The vaccine is offered free of } \\
\text { charge to young girls in } \\
\text { school and to older girls at } \\
\text { the primary care centres } \\
\text { The vaccine gives best } \\
\text { protection before exposure to } \\
\text { HPV. Therefore it is } \\
\text { recommended to vaccinate } \\
\text { before sexual debut }\end{array}$ & $\begin{array}{l}\text { How can HPV be } \\
\text { prevented? } \\
\text { The HPV vaccine is highly } \\
\text { efficient against the most } \\
\text { common HPV types that } \\
\text { can cause cervical cancer } \\
\text { and condyloma (genital } \\
\text { warts) } \\
\text { The vaccine is offered free } \\
\text { of charge to 11-year-old } \\
\text { girls in the school and to } \\
\text { older girls at the primary } \\
\text { care centres. Note! You, } \\
\text { as school nurse, shall } \\
\text { inform where (at what } \\
\text { primary care centre) the } \\
\text { student can be vaccinated } \\
\text { free of charge in your area } \\
\text { The vaccine gives best } \\
\text { protection before exposure } \\
\text { to HPV; therefore it is best } \\
\text { to vaccinate before sexual } \\
\text { debut, but you can also be } \\
\text { vaccinated later on }\end{array}$ \\
\hline
\end{tabular}

HPV, human papillomavirus.

- The importance for girls to attend future cervical cancer screening controls.

The leaflet consisted of 12 pages that included similar information and also an HPV quiz, as well as links to the national online youth clinic, the homepage of the university where the researchers worked and contact information to the authors. After the follow-up questionnaire was completed, students in the intervention group were provided with condoms. Students in the control group only received standard treatment, that is, the regular health interview, as described above.

\section{Outcome measures}

The outcomes pertain to the individual student. Primary outcomes: intention to use condom with a new partner and beliefs towards primary prevention about HPV (strongly agree to strongly disagree, see online supplementary appendix).

Secondary outcomes: increased HPV vaccination (yes/ no/do not know) and increased condom use (yes/no).

\section{Pilot study}

In early 2014, the intervention procedure, including the educational material and questionnaire, was tested by three school nurses among 45 students aged 16 years. The nurses' experiences resulted in minor revisions: for logistic reasons the intervention procedure was modified to having the follow-up for all students together in the classroom, instead of having individual follow-ups at the 
school nurses office. Furthermore, the educational material was shortened, some statements were simplified and the additional response alternative 'do not know' was added to the block of questions regarding beliefs about HPV. A few of the questions were clarified; two were considered redundant and therefore these were removed. In parallel, the questionnaire was tested among adolescents aged 17 years $(\mathrm{n}=230)^{34}$ and they confirmed the school nurses' observations.

\section{Instrument}

The questionnaire was based on previous research and clinical experience. The questions about beliefs, awareness and knowledge about HPV $(\mathrm{n}=24)$ were adapted from our previous study, ${ }^{15}$ and these had multiple choice alternatives and six-point verbal rating scales (Likert scale) from 'Totally agree' to 'Totally disagree', including 'Do not know'. The demographic background questions $(\mathrm{n}=14)$ were taken from the national questionnaire for adolescents, ${ }^{35}$ and the questions regarding sexual behaviour $(n=17)$ were based on a project carried out on university students that has been used repeatedly since $1989 .{ }^{10}$ The questions about beliefs towards primary prevention of HPV according to the HBM constructs on susceptibility comprised questions regarding the risk of contracting HPV; while severity included questions on how serious it would be to receive an HPV infection or cancer. In addition, questions about benefits comprised confidence in vaccine effectiveness and intention to vaccinate, while barriers embraced the individual's perceived barriers for HPV vaccination such as fear of needles and difficulties encountered while booking an appointment for vaccination.

\section{Validity and reliability of the intervention, including the questionnaire}

The validity and reliability were rigorously tested with both qualitative and quantitative methods. Two focus group interviews were undertaken with adolescents $(n=8)$ aged 16-17 years (both boys and girls) who were asked what they considered important to include in an intervention regarding prevention of HPV. Cognitive interviews $(n=5)$ and discussion sessions $(\mathrm{n}=8)$ regarding the questionnaire were performed with adolescents aged 15-18 years.

To test the stability and reliability of the intervention over time, a test-retest evaluation was undertaken in 2014 with first year upper secondary school students $(n=29)$ randomly selected from a school in a city of 200000 inhabitants that was located in mid-Sweden. The questionnaire was distributed on two occasions with a time interval of 2 weeks. Analysis was based on Cronbach's $\alpha$ and showed high reliability scores for the questions regarding the decision-making process relating to HPV vaccination (0.800-0.998), except for the single question 'Do you want to be vaccinated later' (0.436). Statements regarding beliefs about HPV ranged from low to high (scores 0.331-0.918); consequently, two statements were removed.

\section{Ethical considerations}

The study was conducted according to the Declaration of Helsinki. All participants received oral and written information before giving their written consent. The participants were informed that participation was voluntary, that they could withdraw participation at any time without providing a motivation or incurring any negative consequences for themselves. They were also informed that only the researchers would have access to the data, and that all data would be presented at a group level. Contact details to the researchers were provided in case of further questions. According to the Swedish law, children above 15 years of age who understand what participation means have the right to give informed consent regarding participation in research studies. ${ }^{36}$ Therefore, informed consent was not obtained from the parents. We asked permission to conduct the study from the head of the school health facility in each municipality and from the principals of the schools.

\section{Education to school nurses}

All participating school nurses $(n=20)$ received written and verbal instructions, and participated in educational sessions (with MG and CS) scheduled for about $2 \mathrm{~h}$. The education comprised factual information about HPV and the HPV vaccine. The flipchart educational material was presented, and the nurses were encouraged to give comments if anything was unclear or if anything they considered as important was missing. Furthermore, each school nurse received a minimum of $1 \mathrm{~h}$ additional education at the time for the start of the intervention at the school where she worked. During the intervention, the nurses were contacted on a weekly basis.

\section{Sample size calculation}

The power calculation was based on a previous study of the research group ${ }^{37}$ and clinical experience. The sample size of 400 participants per study arm were based on assumptions of a baseline intention to use condom if new partner of $60 \%$, with a power of $80 \%$ to detect differences of 10 percentage points between intervention and control group at a significance level of $5 \%$ (356/study arm IG/CG, a dropout of $10 \%$ and missing values $=400$ ).

\section{Statistical analysis}

For descriptive statistics, categorical data are presented as frequencies and percentages, $\mathrm{n}(\%)$; ordinal data as medians, means and SDs; while continuous data are given as mean and SD. Differences between the intervention and control groups are tested with Pearson's $\chi^{2}$ test for categorical data, Mann-Whitney test for ordinal data, and Student's independent samples $t$ test for continuous data.

The effects of the intervention were measured from baseline at follow-up. First, the HBM scores were calculated by measuring the difference between baseline and at follow-up for each HBM question. Then the questions were grouped together according to the HBM constructs susceptibility, severity, benefits and barriers. Finally, the total 
HBM index was calculated by adding all HBM constructs together. For each individual item in the HBM index, the answers on the 5-point Likert scale ('strongly agree' to 'strongly disagree') where scored 0 to 4 for negative questions (ie, when 'strongly disagree' implied higher health beliefs while 'strongly agree' implied lower health beliefs) and 4 to 0 for positive questions (ie, when 'strongly disagree' implied lower health beliefs while 'strongly agree' implied higher health beliefs). 'Do not know' was classified as an answer for the neutral option. Finally, scores from all included individuals were summarised to give a total score. The McNemar test was used to determine differences in actual HPV vaccinations and actual condom use from baseline to follow-up; we have excluded the 'do not know' group for vaccination in the analysis. The analyses are conducted at an individual level and are based on intention-to-treat principle; these comprise all the 741 students completing the follow-up questionnaire.

In order to take into account the dependence between students who were informed by the same school nurse, generalised estimating equations models were used for examining the results of the intervention on the outcome measures. The differences between the outcome variables at baseline and follow-up were used as dependent variables in the generalised estimating equations models, while the treatment group (intervention or control) was used as a predictor together with the socioeconomic and demographic variables, sex and immigrant background, which differed significantly between the two groups at baseline. These variables were only included as main effects in the regression models, with no interaction being used. In all the analyses, a two-sided $\mathrm{p}$ value $<0.05$ was considered as statistically significant. All analyses were performed in IBM SPSS Statistics V.22.0.

\section{RESULTS}

\section{Participants and sample}

As mentioned above, a flow chart with details of the participants and samples is presented in figure 1. A total of 2883 adolescents in 113 classes were allocated to either the intervention group or control group. We excluded 496 adolescents for not meeting the inclusion criteria. Of the 832 adolescents invited to participate, 81 declined, resulting in a total of 751 participants (ie, the response rate was 90.2\%); 394 in the intervention and 357 in the control group. At follow-up after 3 months, $741(89.1 \%)$ adolescents participated and were analysed (intervention group $\mathrm{n}=390$ and control group $\mathrm{n}=351$ ).

Baseline characteristics of participants by randomised group are presented in table 2. The mean age was 16.1 years, $46.8 \%$ attended theoretical and $53.2 \%$ vocational programmes. More than a quarter $(27.8 \%)$ had an immigrant background and over half of the girls $(56.1 \%)$ were already vaccinated against HPV. There were significant differences between the groups at baseline regarding sex and immigrant background (table 2). The reason for this is given in the Discussion section below. The effects of the intervention, adjusted for treatment group (intervention or control), sex and immigrant background, are presented in tables 3 and 4 . The adjusted analyses are further elaborated below. Since the generalised estimating equations model did not converge for the HBM construct benefits, results for this construct are not presented.

The mean time from baseline to follow-up was 3.26 months, with no differences between intervention and control groups. In some classes, the health interviews were delayed due to the fact that some students participated in practical training, national examinations or other mandatory school activities. Consequently, the follow-up questionnaire was sometimes delayed for a maximum of 2 months.

\section{Effect of the intervention \\ Condom use}

The intervention resulted in increased intention to use a condom with a new partner, with 1.751 higher points score for the intervention than the control group $(p=0.004)$. There were significant changes from baseline to follow-up due to gender ( $\mathrm{p}=0.045)$, with boys having 1.355 points higher score than girls, while there were no significant differences due to immigrant background ( $p=0.717$; table 3 ). Still, there were no significant differences between the intervention and the control groups regarding their reports of actual condom use during their latest act of intercourse $(\mathrm{p}=0.377)$.

\section{HBM total score}

The intervention had a significant effect on HBM total score $(p=0.003)$, (ie, the students perceived more benefits of vaccination, perceived themselves to be at increased risk for an HPV infection or HPV-related disease, considered HPV-related disease a severe threat and perceived fewer barriers against HPV vaccination), with a 2.559 points higher score for the intervention compared to the control group; for further details see table 4 . There were also differences in changes from baseline to follow-up due to gender and immigrant background. Notably, boys had significantly lower scores $(p=0.003)$ compared to girls. Students with immigrant background, however, had a 3.291 points higher score compared to non-immigrant students $(\mathrm{p}=0.003)$.

\section{Susceptibility}

The intervention group reported higher scores for susceptibility $(\mathrm{p}<0.001)$ (ie, they perceived increased risk for HPV infection and HPV-related disease) with a 1.675 points higher score compared to the control group; for details see table 4 . On the other hand, boys had again significantly lower scores for this outcome parameter compared to girls $(p<0.001)$. In contrast, adolescents with an immigrant background had a 1.770 points higher score $(p<0.001)$ and thus perceived increased risk, compared to non-immigrants. 
Table 2 Baseline characteristics of participants by randomised group $(n=741)$

\begin{tabular}{|c|c|c|c|}
\hline Characteristic & Intervention $\mathrm{n}=390$ (52.6\%) & Control n=351 (47.4\%) & p Value \\
\hline Age (years) mean (MD) (SD) & $16.15(16)(0.77)$ & $16.06(16)(0.73)$ & $0.800^{*}$ \\
\hline Sex & & & $<0.001 \dagger$ \\
\hline Female & $239(61.4)$ & $146(41.6)$ & \\
\hline Male & $150(38.6)$ & $205(58.4)$ & \\
\hline Education & & & $0.117 \dagger$ \\
\hline Theoretical programme & $172(44.1)$ & $176(50.1)$ & \\
\hline Vocational programme & 218 (55.9) & 175 (49.9) & \\
\hline Immigrant background $\ddagger$ & & & $0.017 \dagger$ \\
\hline Yes & $123(31.5)$ & $83(23.6)$ & \\
\hline No & 267 (68.5) & $268(76.4)$ & \\
\hline Educational level, mother§ & & & $0.799 \emptyset$ \\
\hline University & $167(54.9)$ & $158(53.7)$ & \\
\hline Upper secondary school & $118(38.8)$ & $118(40.1)$ & \\
\hline Elementary school & 19 (6.3) & $18(6.1)$ & \\
\hline Educational level, father§ & & & $0.334 \uparrow$ \\
\hline University & $100(36.2)$ & $112(39.9)$ & \\
\hline Upper secondary school & $145(52.5)$ & $142(50.5)$ & \\
\hline Elementary school & 31 (11.2) & $27(9.6)$ & \\
\hline Main occupation, mother & & & $0.148 \dagger$ \\
\hline Employed $^{\star *}$ & $339(87.1)$ & $315(90.5)$ & \\
\hline Unemployed†† & $50(12.9)$ & $33(9.5)$ & \\
\hline Main occupation, father & & & $0.095 \dagger$ \\
\hline Employed $^{\star \star}$ & $331(92.5)$ & $318(92.5)$ & \\
\hline Unemployed†† & $27(7.5)$ & $15(4.5)$ & \\
\hline Tobacco use (smoking) & & & $0.197 \dagger$ \\
\hline Never & $316(81.0)$ & 297 (84.6) & \\
\hline Occasionally/daily & $74(19.0)$ & $54(15.4)$ & \\
\hline Tobacco use (snuff) & & & $0.767 \dagger$ \\
\hline Never & $359(92.1)$ & $321(91.5)$ & \\
\hline Occasionally/daily & $31(7.9)$ & $30(8.5)$ & \\
\hline Alcohol consumption & & & $0.284 \dagger$ \\
\hline Never & $257(66.1)$ & $218(62.3)$ & \\
\hline Occasionally/monthly/weekly & $132(33.9)$ & $132(37.7)$ & \\
\hline 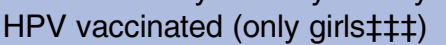 & & & $0.103 \dagger$ \\
\hline Yes & $126(52.7)$ & $89(60.9)$ & \\
\hline No & 83 (34.9) & $47(32.4)$ & \\
\hline Do not know & 29 (12.2) & $9(6.2)$ & \\
\hline \multicolumn{4}{|c|}{ 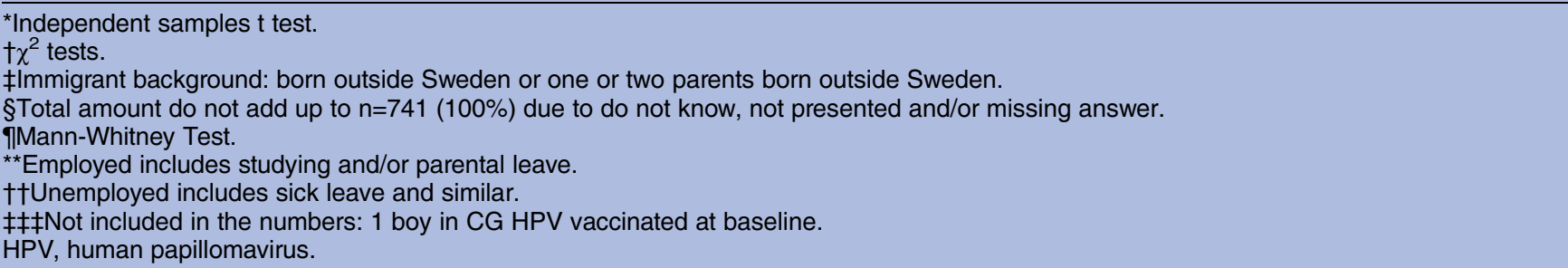 } \\
\hline
\end{tabular}

\section{Severity}

The intervention also had significant effect on severity $(\mathrm{p}<0.001)$, with a 0.409 point higher score (ie, higher perceived HPV severity) for the intervention group compared to the control group; for details see table 4. Boys had again significantly lower scores than girls $(\mathrm{p}<0.001)$, while there were no significant changes from baseline to follow-up due to immigrant background $(\mathrm{p}=0.330)$.

\section{Barriers}

There were no significant differences between the intervention and the control group for this parameter
( $p=0.262)$; for further details see table 4 . Notably, there were a significant change from baseline to follow-up due to gender $(\mathrm{p}=0.015)$, with a 0.469 point higher score for boys (ie, boys perceived lower barriers against HPV vaccination) compared to girls. The observed change for individuals with an immigrant background, on the other hand, was the opposite $(\mathrm{p}=0.014)$.

\section{HPV vaccination}

The intervention increased the likelihood of the students to actually become vaccinated. The proportion of vaccinated girls in the intervention group was $52.5 \%$ 
Table 3 Results of the generalised estimating equations analyses

\begin{tabular}{|c|c|c|c|}
\hline Outcome & Predictors & $\begin{array}{l}\text { Adjusted* } \\
\text { Slope coefficient } \\
(95 \% \mathrm{Cl})\end{array}$ & p Value \\
\hline \multirow{3}{*}{$\begin{array}{l}\text { Intention } \\
\text { to use } \\
\text { condom } \\
\text { if new } \\
\text { partner }\end{array}$} & Intervention & 1.751 & 0.004 \\
\hline & Boys & 1.355 (0.031 to 2.679$)$ & 0.045 \\
\hline & Immigrant & $0.132(-0.580$ to 0.844$)$ & 0.717 \\
\hline \multicolumn{4}{|c|}{$\begin{array}{l}\text { Effect of the intervention for the main outcome-intention to use } \\
\text { condom if new partner. } \\
{ }^{*} \text { Adjusted for treatment group (intervention or control group), sex } \\
\text { and immigrant background. }\end{array}$} \\
\hline
\end{tabular}

before and $59 \%$ after the intervention, whereas no difference over time was seen in the control group $(60.9 \%)$. This difference was significant $(p=0.02)$. In actual numbers, 15 girls and 1 boy received the vaccine between the intervention and completion of the follow-up questionnaire. In addition, 1 girl wanted to be vaccinated, but her parents did not give their consent.

No harmful effects of the intervention were reported.

\section{DISCUSSION}

\section{Principal findings}

This randomised controlled trial of a school-based educational session showed that adolescents' beliefs and behaviour regarding HPV prevention can successfully be improved. After the intervention, the students had significantly more favourable beliefs towards HPV prevention, and were more inclined to use condom during sex with a new partner. In addition, the intervention increased actual HPV vaccination rates.

It is encouraging that the changes from baseline to follow-up on the intention to use condom was higher among boys than among girls, since they are neither included in the national HPV vaccination programme nor receive any organised information about HPV. Our finding gives support for the speculation that boys also want to protect themselves and their partners against the virus.

It was frustrating that the effects on the students' intentions did not result in clear differences in actual reported condom use. However, it should be kept in mind that this is a small group and the follow-up was short. The results might have been different with a longer follow-up-not all of them were sexually active, and those who were may not have had a new opportunity to use a condom with a new partner during the period between the intervention and the follow-up questionnaire. Consequently, too much weight should not be given to this finding. More important is the finding that several girls (and 1 boy) chose to have themselves vaccinated shortly after the intervention. Since the older girls are offered the vaccine in the catch-up programme and the families have to personally contact the primary care centre to book an appointment, it is encouraging that the intervention had effects on the vaccination rates.

There were significant effects on the HBM total score, which includes the parameters perceived susceptibility, perceived severity, perceived benefits and perceived barriers. Interestingly, the increase in beliefs about HPV prevention from baseline to follow-up was higher among adolescents with an immigrant background. This is an important finding since Sweden is a multicultural country, with many immigrants from countries with limited access to healthcare and health education. It was also encouraging that these students reported higher scores for perceived susceptibility, that is, they were aware of the risks. Immigrant background is known to be associated with increased risk for cervical cancer ${ }^{38}$ and lower attendance in cervical cancer screening programmes. ${ }^{39} 40$

We also found significant differences between the intervention and control groups regarding perceived

Table 4 Results of the generalised estimating equations analyses

\begin{tabular}{llcr}
\hline & Predictors & Adjusted & p Value \\
Outcome & Slope coefficient (95\% Cl) & 0.003 \\
\hline HBM total score & Intervention & $2.559(0.875$ to 4.324$)$ & 0.003 \\
& Boys & $-2.244(-3.729$ to -0.759$)$ & 0.003 \\
Susceptibility & Immigrant & $3.291(1.107$ to 5.474$)$ & $<0.001$ \\
& Intervention & $1.675(0.850$ to 2.500$)$ & $<0.001$ \\
Soys & $-1.544(-2.172$ to -0.916$)$ & $<0.001$ \\
Severity & Immigrant & $1.770(0.953$ to 2.587$)$ & $<0.001$ \\
& Intervention & $0.409(0.183$ to 0.634$)$ & $<0.001$ \\
Barriers & Boys & $-0.339(-0.490$ to -0.187$)$ & 0.330 \\
& Immigrant & $0.131(-0.133$ to 0.395$)$ & 0.262 \\
& Intervention & $-0.172(-0.473$ to 0.129$)$ & 0.015 \\
& Boys & $0.469(0.091$ to 0.845$)$ & 0.014 \\
\hline
\end{tabular}

Effect of the intervention according to the Health Belief Model (HBM)

${ }^{*}$ Adjusted for treatment group (intervention or control group), sex and immigrant background. 
severity. According to HBM, the combination of susceptibility and severity are labelled as perceived threat. ${ }^{33}$ Since adolescence is a time in life when the perception of being at risk of contracting a sexually transmitted infection is generally low, especially among boys, ${ }^{41}$ and the sexual risk taking is increasing, ${ }^{11}$ we are happy to note that the intervention increased the adolescents' perception of HPV as a serious threat. This is beneficial for their future sexual health behaviour.

\section{Strengths}

This complex educational intervention was carefully developed, standardised, validated, and monitored, and it had a high response rate; $89.1 \%$ completed the study. Further major strengths are the randomised control trial design and the fact that various kinds of schools with a representative sample of both boys and girls were included. The percentage of adolescents with an immigrant background, as well as the number of HPV-vaccinated girls at baseline, are representative for the Swedish population in general. This means that the findings can, with a fair degree of certainty, be extrapolated to the population at large. The target group, adolescents aged 16 years, is adequate since this is a time in life when many become sexually active. The school nurses, with their professional role and experience of discussing sensitive issues, are the proper persons to deliver the intervention. Finally, a school-based intervention reaches all adolescents regardless of socioeconomic status, ethnicity or cultural background.

\section{Weaknesses}

For logistic reasons, we could not randomise the students one by one, since the school nurses could not perform the follow-up at an individual level. This became clear during the evaluation of the pilot study. Consequently, the groups differed somewhat at baseline with, for example, more girls in the intervention group and more boys in the control group. We took this into account in the generalised estimating equations model and adjusted for the demographic differences at baseline.

It is possible that the participating school nurses are more committed to HPV prevention and sexual health issues than their colleagues. These nurses' commitment and personal communication skills might have affected the outcome of the intervention in a favourable direction. To compensate for this and ensure uniformity, the intervention was highly structured, the school nurses were provided with exhaustive instructions, and the researchers regularly contacted them, asking questions systematically about 'how does it work for you?'. The initial process evaluation and $\log$ lists indicate that the fidelity was very high; all school nurses performed the intervention according to the given guidelines. Also, as in all studies including self-reported questionnaires, there is a risk of participants' over-reporting or under-reporting or having recall bias; however, we consider this risk to be small in the present study.

Finally, although our study was fairly large, it would have been even better if we had been able to include more participants in order to be able to go into further detail and perform more subgroup analyses.

\section{Strengths and weaknesses in relation to other studies}

To our knowledge this is the first randomised, educational, school-based face-to-face intervention study among a diverse population of adolescents with the aim to improve primary prevention of HPV. Previous studies have mainly been undertaken among young adult women. ${ }^{26}{ }^{30}$ As discussed in the systematic review by Shepherd $e t a l,{ }^{42}$ there is a need for interventions with greater focus on HPV and especially for the link between HPV and cancer. Previous interventions have tended to focus on prevention of cervical cancer only. ${ }^{42}$ It is also an advantage to use a theoretical framework such as HBM when developing an educational intervention with preventive aims. HBM is a systematic way to explain a person's health behavior and therefore this clarifies the use of key concepts on which the intervention is based. ${ }^{33}$

Our results stand in contrast to previous school-based interventions delivered in the class for which no significant effects on beliefs ${ }^{19}$ neither about condom use nor HPV vaccination, were found. ${ }^{19}{ }^{20}$ This discrepancy indicates that it is beneficial to have a face-to-face intervention delivered by school nurses; similar interventions have previously been delivered by the researchers. ${ }^{19} 2024$

\section{Implications}

The results indicate that an educational intervention delivered by healthcare providers, such as school nurses, is a highly feasible and effective way to increase adolescents' beliefs and behaviour towards primary prevention of HPV, regardless of socioeconomic status, ethnicity or cultural background.

\section{Unanswered questions and future research}

Larger studies with more participants may help understand if there are also further differences between girls and boys, and between students with or without an immigrant background. Some of our conclusions remain speculative and await the outcomes of further such studies. In addition, studies with longer follow-up are needed in order to find out if school-based educational interventions are effective in the long term, and if the participants' actual behaviour changes in the desired direction.

\section{Author affiliations}

${ }^{1}$ Department of Public Health and Caring Sciences, Uppsala University, Uppsala, Sweden

${ }^{2}$ Centre for Clinical Research Västerås, Uppsala University, Västerås, Sweden ${ }^{3}$ Department of Women's and Children's Health, Uppsala University, Uppsala, Sweden

${ }^{4}$ Department of Health and Caring Sciences, Linnaeus University, Kalmar, Sweden 
${ }^{5}$ Centre for Research and Development, Uppsala University/Region of Gävleborg, Gävle, Sweden

${ }^{6}$ Department of Oncology-Pathology, Karolinska Institutet, Karolinska University Hospital, Stockholm, Sweden

Acknowledgements The authors thank all the participants, especially the school nurses and the adolescents. The authors also thank the heads of the school health facility in each municipality and the principals of the schools. Special thanks to the Swedish Association of School Nurses for their support, and for allowing us to present the project at the national conference. In addition, the authors thank Åke Pålshammar for valuable discussions about the project, especially about adolescents' psychosocial and cognitive development.

Contributors MG conceptualised and designed the study, recruited participants, managed the data collection, completed data analysis and interpretation, wrote the draft manuscript, and obtained funding. AR assisted in the design, data analysis and interpretation, funding and manuscript preparation. CS assisted in design, participant recruitment, data collection, data interpretation, manuscript preparation and funding. ML, MO, RW and TT assisted in design, data collection, data interpretation, manuscript preparations and funding. BA and TD assisted in the design, data interpretation and funding, and were available for clinical consultation. TN assisted in all activities, including design, data interpretation, data collection, manuscript preparation and funding. All authors made critical comments on drafts of the manuscript. All authors had full access to all of the data in the study, and take responsibility for the integrity of the data and the accuracy of the data analysis.

Funding This work was supported by (the Swedish Cancer Society) grant number (130744), (Uppsala-Örebro Regional Research Council) grant number (RFR-387561/476021) and (Uppsala County Council) grant number (LUL-347931), (the Swedish Government Funds for Clinical Research) grant number (19049/470102/44957) and the (Medical Faculty at Uppsala University) grant number (2012/278). In addition, MG and CS received a scholarship from the Gillbergska Foundation. The sponsors had no role in the design and conduct of the study; collection, management, analysis, and interpretation of the data; preparation, review, or approval of the manuscript; and decision to submit the manuscript for publication.

Competing interests None declared.

Ethics approval Uppsala University, Department of Public Health and Caring Sciences, and the Regional Ethical Committee in Uppsala, Sweden, D.nr. 2013/324 approved this study. All participants gave informed consent.

Provenance and peer review Not commissioned; externally peer reviewed.

Data sharing statement No additional data are available.

Open Access This is an Open Access article distributed in accordance with the Creative Commons Attribution Non Commercial (CC BY-NC 4.0) license, which permits others to distribute, remix, adapt, build upon this work noncommercially, and license their derivative works on different terms, provided the original work is properly cited and the use is non-commercial. See: http:// creativecommons.org/licenses/by-nc/4.0/

\section{REFERENCES}

1. Forman D, de Martel C, Lacey CJ, et al. Global burden of human papillomavirus and related diseases. Vaccine 2012;30(Suppl 5): F12-23.

2. Jemal A, Bray F, Center MM, et al. Global cancer statistics. $C A$ Cancer J Clin 2011;61:69-90.

3. Paavonen J, Jenkins D, Bosch FX, et al. Efficacy of a prophylactic adjuvanted bivalent L1 virus-like-particle vaccine against infection with human papillomavirus types 16 and 18 in young women: an interim analysis of a phase III double-blind, randomised controlled trial. Lancet 2007;369:2161-70.

4. Lu B, Kumar A, Castellsagué X, et al. Efficacy and safety of prophylactic vaccines against cervical HPV infection and diseases among women: a systematic review \& meta-analysis. BMC Infect Dis 2011;11:13
5. Leval A, Herweijer E, Ploner A, et al. Quadrivalent human papillomavirus vaccine effectiveness: a Swedish national cohort study. J Natl Cancer Inst 2013;105:469-74.

6. Nielson CM, Harris RB, Nyitray A, et al. Consistent condom use is associated with lower prevalence of human papillomavirus infection in men. J Infect Dis 2010;15:445-51.

7. Winer RL, Hughes JP, Feng Q, et al. Condom use and the risk of genital human papillomavirus infection in young women. $N$ Engl J Med 2006;354:2645-54.

8. Markowitz LE, Tsu V, Deeks SL, et al. Human papillomavirus vaccine introduction-the first five years. Vaccine 2012;30(Suppl 5): F139-48.

9. Public Health Agency of Sweden. The childhood immunization program in Sweden 2013. Stockholm, 2014:76. http://www. folkhalsomyndigheten.se/amnesomraden/smittskydd-och-sjukdomar/ vaccinationer/vaccinationsregister/ (accessed 5 Aug 2015).

10. Stenhammar C, Ehrsson YT, Åkerud H, et al. Sexual and contraceptive behavior among female university students in Sweden -repeated surveys over a 25-year period. Acta Obstet Gynecol Scand 2015;94:253-9.

11. Herlitz CA, Forsberg M. Sexual behaviour and risk assessment in different age cohorts in the general population of Sweden (19892007). Scand J Public Health 2010;38:32-9.

12. Johnson AM, Mercer $\mathrm{CH}$, Beddows $\mathrm{S}$, et al. Epidemiology of, and behavioural risk factors for, sexually transmitted human papillomavirus infection in men and women in Britain. Sex Transm Infect 2012;8:212-17.

13. Ramqvist T, Dalianis T. An epidemic of oropharyngeal squamous cell carcinoma (OSCC) due to human papillomavirus (HPV) infection and aspects of treatment and prevention. Anticancer Research 2011;31:1515-19.

14. Du J, Nordfors $\mathrm{C}$, Ahrlund-Richter A, et al. Prevalence of oral human papillomavirus infection among youth, Sweden. Emerg Infect Dis 2012;18:1468-71.

15. Grandahl M, Tydén T, Rosenblad A, et al. School nurses' attitudes and experiences regarding the human papillomavirus vaccination programme in Sweden: a population-based survey. BMC Public Health 2014;14:540.

16. Grandahl M, Oscarsson M, Stenhammar C, et al. Not the right time: why parents refuse to let their daughters have the human papillomavirus vaccination. Acta Paediatr 2014;103:436-41.

17. Gottvall M, Grandahl M, Höglund AT, et al. Trust versus concerns-how parents reason when they accept HPV vaccination for their young daughter. Ups J Med Sci 2013;118:263-70.

18. Mattebo M, Grün N, Rosenblad A, et al. Sexual experiences in relation to HPV vaccination status in female high school students in Sweden. Eur J Contracept Reprod Health Care 2014;19:86-92.

19. Gottvall M, Tydén T, Höglund AT, et al. Knowledge of human papillomavirus among high school students can be increased by an educational intervention. Int J STD AIDS 2010;21:558-62.

20. Marek E, Dergez T, Rebek-Nagy G, et al. Adolescents' awareness of HPV infections and attitudes towards HPV vaccination 3 years following the introduction of the HPV vaccine in Hungary. Vaccine 2011;29:8591-8.

21. DiClemente RJ, Wingood GM, Sales JM, et al. Efficacy of a telephone-delivered sexually transmitted infection/human immunodeficiency virus prevention maintenance intervention for adolescents: a randomized clinical trial. JAMA Pediatr 2014;168:938-46.

22. Coyle KK, Glassman JR, Franks HM, et al. Interventions to reduce sexual risk behaviors among youth in alternative schools: a randomized controlled trial. J Adolesc Health 2013;53:68-78.

23. Wingood GM, Diclemente RJ, Robinson-Simpson L, et al. Efficacy of an HIV intervention in reducing high-risk human papillomavirus, nonviral sexually transmitted infections, and concurrency among African American women: a randomized-controlled trial. J Acquir Immune Defic Syndr 2013;63(Suppl 1):S36-43.

24. Kwan TT, Tam KF, Lee PW, et al. The effect of school-based cervical cancer education on perceptions towards human papillomavirus vaccination among Hong Kong Chinese adolescent girls. Patient Educ Couns 2011;84:118-22.

25. Rand $\mathrm{CM}$, Brill $\mathrm{H}$, Albertin $\mathrm{C}$, et al. Effectiveness of centralized text message reminders on human papillomavirus immunization coverage for publicly insured adolescents. J Adolesc Health 2015;56 (5 Suppl):S17-20.

26. Fu LY, Bonhomme LA, Cooper SC, et al. Educational interventions to increase HPV vaccination acceptance: a systematic review. Vaccine 2014;32:1901-20.

27. Gilkey MB, Dayton AM, Moss JL, et al. Increasing provision of adolescent vaccines in primary care: a randomized controlled trial. Pediatrics 2014;134:e346-53. 
28. Statistics Sweden Secondary Statistics Sweden 2013. http://www. scb.se/sv /Hitta-statistik/Artiklar/Vart-femte-barn-har-utlandskbakgrund/ (accessed 8 Aug 2015).

29. Statue Book of Sweden Education Act 2010:800. [Svensk författningssamling Skollagen 2010:800]. Sweden: The Committee on Education [Utbildningsdepartementet]. 2010.

30. Juraskova I, Bari RA, O'Brien MT, et al. HPV vaccine promotion does referring to both cervical cancer and genital warts affect intended and actual vaccination behavior? Womens Health Issues 2011;21:71-9.

31. Donadiki EM, Jiménez-García R, Hernández-Barrera V, et al. Health Belief Model applied to non-compliance with HPV vaccine among female university students. Public Health 2014;128: 268-73.

32. Roye C, Perlmutter Silverman P, Krauss B. A brief, low-cost, theory-based intervention to promote dual method use by black and Latina female adolescents: a randomized clinical trial. Health Educ Behav 2007:34:608-21.

33. Champion VL, Skinner Sugg $C$. The health belief model. In: Glantz $\mathrm{K}$, Rimer BK, Viswanath K, eds. Health behavior and health education: theory, research and practice. 4th edn. San Fransisco, CA, USA: Jossey-Bass, 2008:45-65.

34. Lundberg M, Färdig M. Gymnasieelevers kunskap om och inställning till HPV och HPV-vaccin. Uppsala University, 2014. http:// www.diva-portal.org/smash/search.jsf?dswid=1347 (accessed 3 Oct 2015).
35. National health questionnaire for adolescents [Liv och hälsa ung] Secondary National health questionnaire for adolescents [Liv och hälsa ung] 2013. http://www.lul.se/sv/Vard-halsa/Liv-halsa/ Liv-och-halsa-ung/ (accessed 15 Feb 2015).

36. CODEX rules and guidelines for research. Secondary CODEX rules and guidelines for research 2015. http://www.codex.vr.se/en/ manniska1.shtml (accessed 4 Oct 2015).

37. Larsson M, Eurenius $\mathrm{K}$, Westerling R, et al. Evaluation of a sexual education intervention among Swedish high school students. Scand J Public Health 2006;34:124-31.

38. Lu PJ, Rodriguez-Lainz A, O'Halloran A, et al. Adult vaccination disparities among foreign-born populations in the U.S., 2012. Am J Prev Med 2014;47:722-33.

39. Azerkan F, Zendehdel K, Tillgren P, et al. Risk of cervical cancer among immigrants by age at immigration and follow-up time in Sweden, from 1968 to 2004. Int J Cancer 2008;123:2664-70.

40. Azerkan F, Sparén P, Sandin S, et al. Cervical screening participation and risk among Swedish-born and immigrant women in Sweden. Int J Cancer 2012;130:937-47.

41. Ekstrand M, Tydén T, Larsson M. Exposing oneself and one's partner to sexual risk-taking as perceived by young Swedish men who requested a Chlamydia test. Eur $J$ Contracept Reprod Health Care 2011:16:100-7.

42. Shepherd JP, Frampton GK, Harris P. Interventions for encouraging sexual behaviours intended to prevent cervical cancer. Cochrane Database Syst Rev 2011;(4):CD001035. 